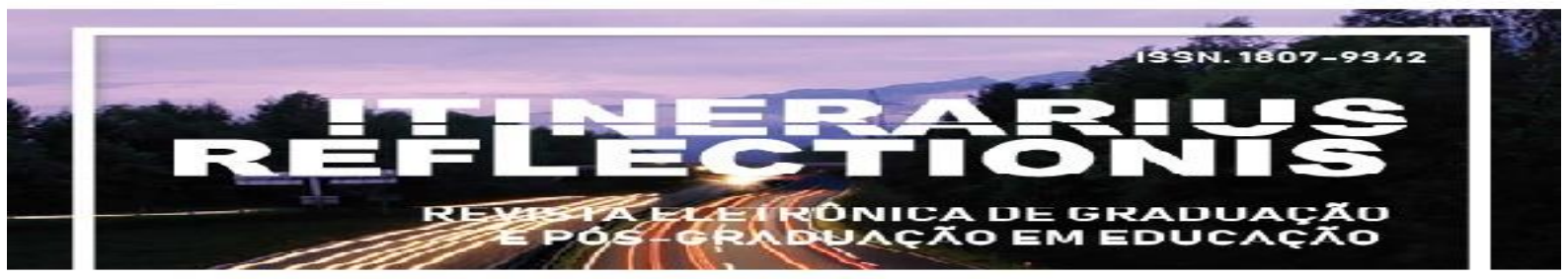

Volume, 15, número, 1, ano 2019

\title{
O INTERESSE PESSOAL E O FATOR PROFESSOR NO PROCESSO DE APRENDIZAGEM DO ALUNO
}

\author{
Lidianne Salvatierra ${ }^{1}$
}

RESUMO: Diversos fatores pedagógicos, sociais e psicológicos são atribuídos ao insucesso e dificuldades do processo de ensino-aprendizagem. $O$ conhecimento desses fatores e a discussão das suas influências são fundamentais para o processo de melhoria da qualidade da educação brasileira. Assim, a presente pesquisa objetivou através do questionamento "Qual a matéria que você mais gosta/gostava? E por quê?" conhecer e discutir os fatores que levam o aluno a gostar mais de uma determinada disciplina. Como resultado da análise de 184 respostas, foi possível identificar dois grandes fatores para a motivação da aprendizagem sobre determinada matéria: (a) o interesse individual, que está relacionado com as características próprias dos alunos; e (b) o fator professor, caracterizado pelas experiências na relação aluno/professor.

Palavras-chave: Processo de ensino-aprendizagem. Motivação. Interação professor-aluno.

\section{THE INDIVIDUAL INTEREST AND THE TEACHER-FACTOR ON STUDENT'S LEARNING PROCESS}

\begin{abstract}
Several pedagogical, social and psychological factors are attributed to the failure and difficulties of the teaching-learning process. The recognition of these factors and the discussion of their influences are fundamental to the process of improving the quality of the Brazilian education in several aspects. Thus, the present research aimed through the student's responses to the question "Which school subject do you like the most? And why?" to know and discuss the factors that led the student to prefer a particular school subject. As a result of the analysis of 184 responses, it was possible to identify two major factors that influence the student's motivation for like and learn a particular school subject: (a) individual interest, which is related to the student's personal characteristics; and (b) the teacher-factor, characterized by the experiences in the student/teacher relationship.
\end{abstract}

Keywords: Teach-learning process. Motivation. Teacher-students interaction.

\section{INTRODUÇÃO}

Os desafios do processo de ensino-aprendizagem são formados por um conjunto de fatores internos e externos (DOURADO e OLIVEIRA, 2009). Estes fatores têm implicações diretas, tanto negativamente quanto positivamente, na qualidade do envolvimento do aluno com o processo. Os fatores internos podem ser divididos em: fatores pessoais, que

\footnotetext{
${ }^{1}$ Universidade Estadual de Roraima Programa de Pós-Graduação em Educação
} 


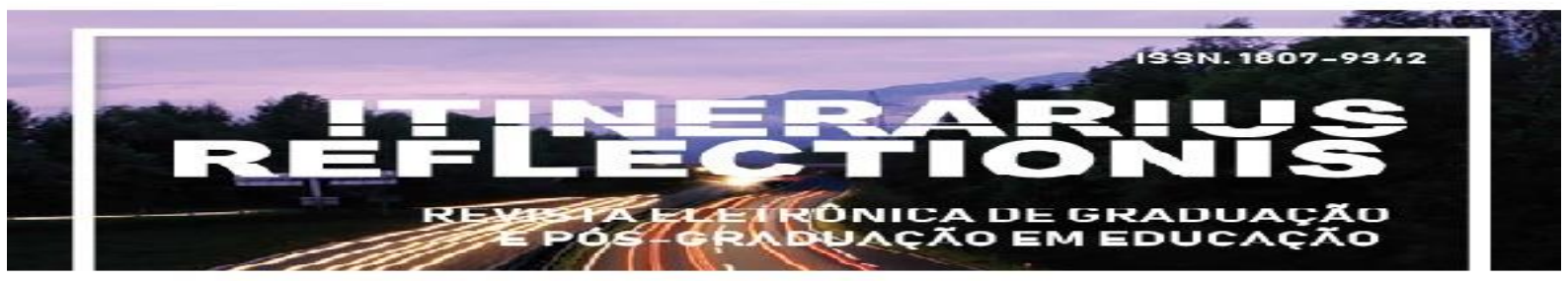

Volume, 15, número, 1, ano 2019

caracterizam a natureza e o desenvolvimento em si do sujeito; e fatores intraescolares, onde o ambiente escolar atua no desenvolvimento e moldagem dos conhecimentos, ações, valores e ideias do indivíduo, e onde os professores, colegas de turma e equipe pedagógica são os atores influenciadores e modificadores. Já os fatores externos, ou extraescolares, aludem ao cenário fora do contexto escolar e reúnem diversos aspectos com grande influência no crescimento e desenvolvimento biopsicossocial do aluno (COLLARES, 1996).

Dentre os fatores internos pessoais, que tratam do individualismo do sujeito e suas relações com os signos, ações, contextos e interesses pessoais (NOVOA, 1992; BUENO, 2016), podem ser destacados a: Motivação, que guia o aluno na busca de novos conhecimentos e contribui no desempenho nas tarefas escolares (BALANCHO e COELHO, 1996; PINTRICH e SCHUNK, 2002); Desmotivação, que é o conceito antônimo do item anterior e influencia negativamente no processo de ensino (GARRIDO, 1990; LENS, 1994); e o Desenvolvimento cognitivo físico, caracterizado pelo desenvolvimento biológico, fisiológico e psicológico do aluno, que pode resultar tanto em dificuldades quanto facilidades de aprendizagem (SHAYWITZ, 2006; WILLCUTT ET AL., 2013).

Os fatores intraescolares no campo do processo de ensino-aprendizagem podem ser analisados do ponto de vista do: Professor, com suas estratégias de ensino, didática e práticas pedagógicas, aproximação e afetividade com os alunos, formação educacional, e relação do professor com a infraestrutura disponível e com a política educacional (SOARES ET AL., 2003; LIBÂNEO ET AL., 2008); Estudante, com a promoção e desenvolvimento de interações sociais com outros alunos e equipe pedagógica, sistema de avaliação de desempenho, casos exitosos de práticas pedagógicas; e Equipe pedagógica, sobre o apoio de ensino, gestão escolar, prática políticas, projetos pedagógicos e outros (SOARES, 2005).

Os principais fatores relacionados ao ambiente extraescolar que interferem no aprendizado do aluno são a: Condição socioeconômica, relativo ao acesso a bens culturais e posses (ALBERNAZ ET AL., 2002); e Influência familiar, interesse demonstrado pela família na educação do aluno, também relacionado às pressões e apoio participativo (FERREIRA e BARREIRA, 2010; SOARES ET AL., 2012).

É importante lembrar que vários desses fatores são retroalimentados entre si e constituem uma complexidade situacional que varia de acordo com a condição histórica, 


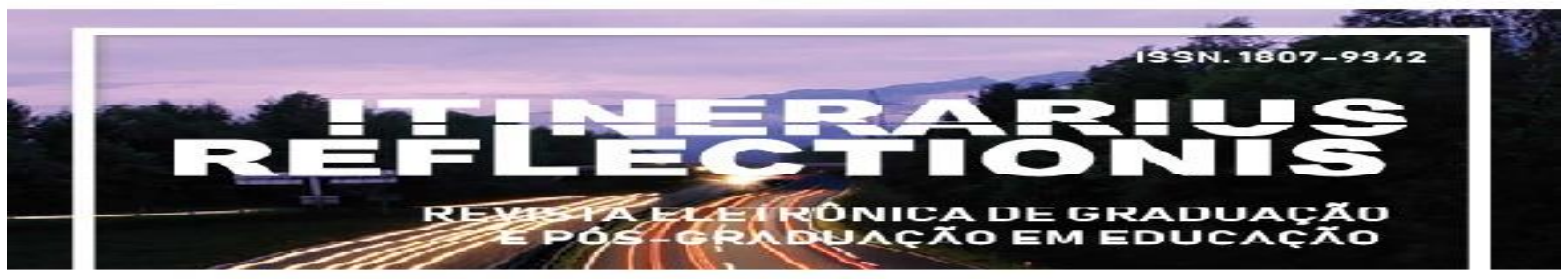

Volume, 15, número, 1, ano 2019

cultural e social em que os indivíduos investigados se encontram. Gatti et al. (1981) destacam, por exemplo, que o fracasso escolar de um aluno pode ser resultado de uma trama interrelacional entre dificuldades de aprendizagem, condições familiares, características profissionais do professor, infraestrutura da escola e contexto social que engloba e determina o aspecto macro do ambiente ao seu redor. Assim, o constante levantamento e análise, sob diferentes ângulos, dos fatores de influência no processo de ensino-aprendizagem são fundamentais para a determinação, avaliação e combate dos problemas da educação brasileira.

O reconhecimento dos elementos que geram avanços e atrasos em uma visão macro no contexto escolar é o primeiro passo para a mudança do paradigma da escola contemporânea. Em uma escala micro e mais específica, o conhecimento dos componentes que interferem no processo de ensino-aprendizagem podem proporcionar dados que podem ser utilizados para a formulação de estratégias visando à melhora na qualidade e desempenho do processo pelo professor, por exemplo. Nesta escala, trabalhos como o de investigações de opiniões, atitudes, preferências e expectativas de alunos com relação a pontos específicos do contexto escolar podem contribuir para o desenvolvimento de abordagens metodológicas para soluções de problemas educacionais procedurais (SOARES ET AL., 2015).

Dessa forma, o presente artigo procurou investigar os principais fatores que levam o indivíduo a gostar mais de uma determinada disciplina em relação à outra no âmbito escolar, relacioná-los com as principais fundamentações biopsicossociais que corroboram para as justificativas apresentadas e discutir a utilização do conhecimento desses fatores no processo de ensino-aprendizagem pelo professor.

\section{PROCEDIMENTO METODOLÓGICO}

Os resultados apresentados aqui são provenientes de um projeto quali-quantitativo correlacional de engajamento dos brasileiros em questões educacionais atuais intitulado "Uso e impacto de mídias sociais na formação de cultura e do letramento científico dos brasileiros". Os dados foram coletados entre Abril e Junho de 2018 por meio de questionário online utilizando recrutamento online via plataforma Reddit. 


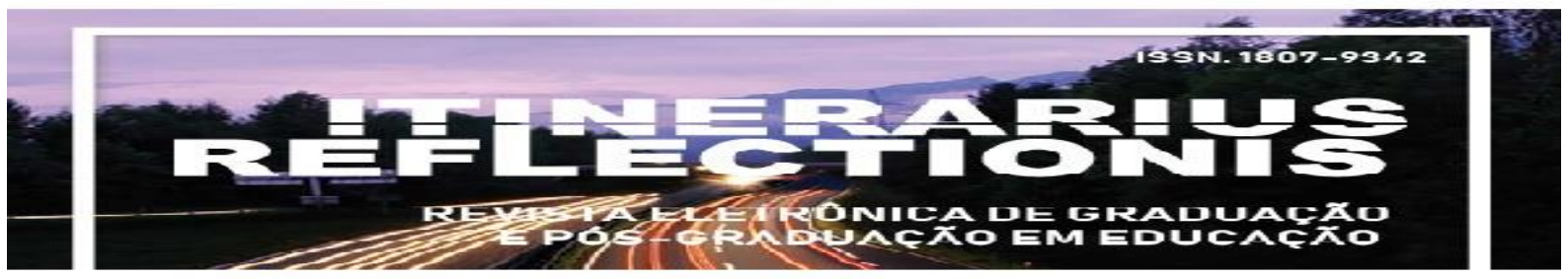

Volume, 15, número, 1, ano 2019

A escolha do Reddit como plataforma de coleta de dados justifica-se pela validação científica contínua da via para a coleta rápida de grande quantidade de dados de amostragem aleatória simples e disponibilização de dados estatísticos finos que permitem a perfilação demográfica (SHATZ, 2016; JAMNIK e LANE, 2017). O questionário foi disponibilizado para 162.272 mil usuários brasileiros em idade de formação educacional (90\% dos usuários entre 18 e 30 anos, e $70 \%$ tendo completado ou cursando o ensino superior). Os duzentos primeiros questionários preenchidos foram pré-análisados, onde quatro questionários foram descartados por inconsistências entre perguntas e respostas ou erros de preenchimento.

O questionário online continha 13 questões abertas e fechadas, das quais: (a) 5 perguntas buscavam formar um perfil dos participantes contendo a idade e formação educacional; e (b) 8 perguntas cujas respostas objetivavam reunir atitudes e opiniões sobre a importância e objetivos da escola, práticas educacionais dos professores, perfil e motivações dos estudantes, problemas educacionais gerais, e percepções pessoais sobre os conteúdos ensinados. Os participantes tiveram completa liberdade de interpretação das perguntas e de estilo de desenvolvimento de respostas. Todos assinaram um termo de consentimento livre esclarecido (TCLE), incluindo autorização para a reprodução e publicação das respostas preservando a identificação do autor.

O presente artigo discute as atitudes e percepções a partir de 196 respostas relacionadas à pergunta "Qual a matéria que você mais gosta/gostava? E por quê?". O principal objetivo da pergunta não foi verificar per si quais as matérias que os participantes mais gostavam ou menos gostavam, e sim conhecer e discutir os fatores que levaram à preferência pela matéria. As demais perguntas do questionário serão utilizadas em futuras análises com objetivos diferente do presente trabalho.

Com relação ao perfil dos participantes, a média de idade foi de 23.5 anos, com presença mais significativa de sujeitos entre 17 e 25 anos. Sobre a formação educacional, 99.5\% (195) dos participantes concluíram o Ensino Básico, 99\% (194) concluíram o Ensino Fundamental e 93.3\% (181) concluíram o Ensino Médio. Dos treze participantes que informaram não terem concluído o Ensino Médio, onze estão no processo de conclusão e apenas dois participantes informaram que evadiram completamente. 


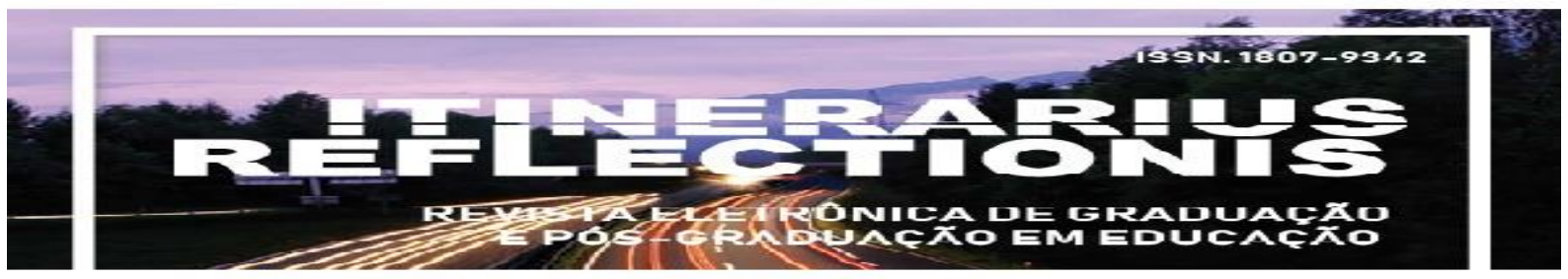

Volume, 15, número, 1, ano 2019

A análise das respostas foi baseada em uma abordagem quantitativa e predominantemente qualitativa com dados descritivos. 83 respostas foram transcritas majoritariamente na íntegra neste artigo, utilizando [...] para indicação de transição parcial, inclusão de frases de contextualização ou de eliminação de palavras para melhorar a compreensão na leitura. As opiniões iguais na forma de escrita foram omitidas.

O método de análise de conteúdo (BARDIN, 2010) foi utilizado para a transformação do conteúdo das respostas em unidades (unitarização) e posterior classificação das unidades em categorias (categorização) a fim de facilitar a discussão.

\section{RESULTADOS E DISCUSSÃO}

Diversas pesquisas buscaram definir e ranquear a preferência de alunos brasileiros com relação às matérias escolares, e como exemplo de alguns resultados obtidos: a Matemática foi a disciplina preferida entre alunos do sexto ano, e também apareceu como preferida junto a Ciência e Educação Física para alunos do nono ano em uma escola pública no Espírito Santo (VIEIRA ET AL., 2017); Educação Física foi indicada como a preferida entre 107 alunos da rede municipal de ensino em São Paulo (SORROCHE, 2011); Biologia e Matemática foram as mais citadas dentre 400 alunos finalistas do ensino médio de Juiz de Fora como as preferidas (FALCO ET AL., 2014); Matemática apareceu em primeiro lugar para alunos do primeiro ano do ensino médio em uma escola particular de Canoas (VARGAS ET AL., 2017); Educação Física seguida de Biologia foram as disciplinas preferidas entre alunos do segundo ano do ensino médio no Espírito Santo (LORENZONI ET AL., 2017); e Matemática foi indicada como a preferida (36\%) em uma pesquisa com 1.700 crianças de 13 capitais brasileiras entre 6 e 9 anos de idade, seguida de Português (17\%) e Artes (10\%) (VIEIRA, 2014).

Neste trabalho com relação à matéria favorita, a disciplina de História foi a mais citada com 25\% ( $\mathrm{n}=59)$, seguida de Matemática com 18\% ( $\mathrm{n}=43)$, Biologia com $12 \%(\mathrm{n}=$ 28) e Física com $11 \%(\mathrm{n}=26)$ (Fig. 1). O resultado deste trabalho com os citados acima indicam que não existe um consenso de qual é a disciplina preferida e que essa preferência 


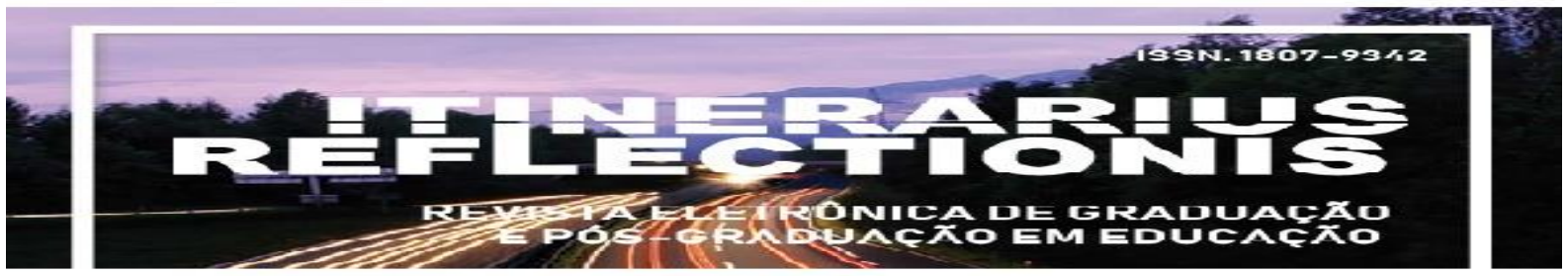

Volume, 15, número, 1, ano 2019

tende a variar com o grupo e o momento questionado, o que indica que fatores internos e externos ao ambiente escolar estão relacionados com esta preferência.

Figura 1. Percentual representativo das matérias preferidas dos participantes. Fonte: autora (2018).

Dos 196 questionários analisados: 184 participantes forneceram 219 justificativas passíveis de categorização; 6 indicaram não ter uma disciplina favorita; 6 participantes indicaram a disciplina favorita, mas não justificaram; e 6 participantes ofereceram justificativas que não puderam ser categorizadas ("Sinceramente nunca tive uma disciplina favorita. Para mim, a escola sempre foi uma obrigação, um "mal necessário"”/ "Nenhuma. Pois as matérias que gosto a escola não ensina como economia e astronomia”). Assim, 219 justificativas de 184 participantes foram agrupadas em duas grandes categorias, sendo: a) Interesse natural no conteúdo da disciplina, classificado como fator externo à escola; e b) Fator professor, como fator interno (Fig. 2).

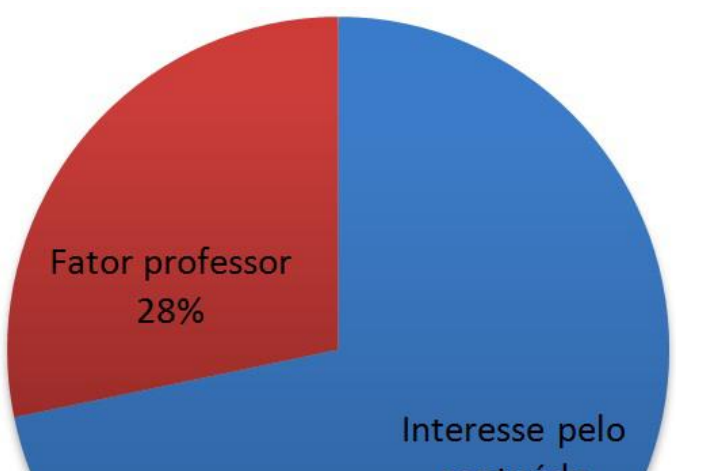




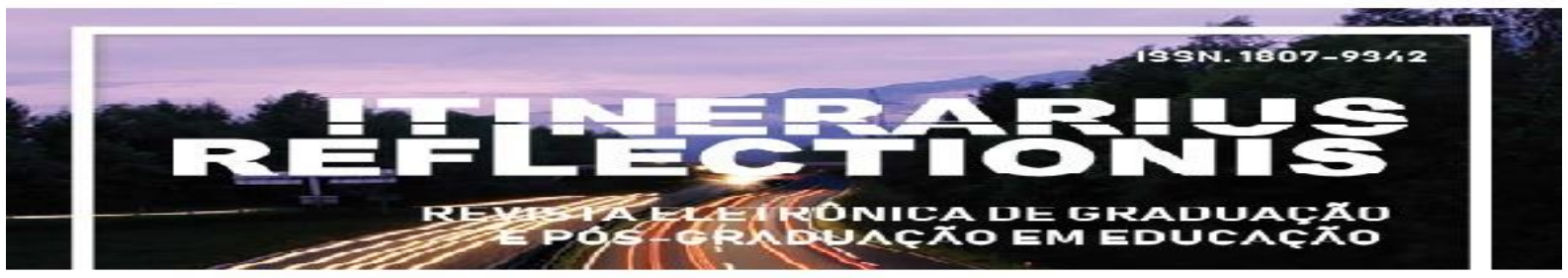

Volume, 15, número, 1, ano 2019

Figura 2. Representação entre o fator interesse e o fator professor como justificativas para a escolha da matéria preferida pelos participantes. Fonte: autora (2018).

\subsection{Fator externo: Interesse no conteúdo da disciplina}

A justificativa mais citada, com $72 \%$ das citações, para a escolha da disciplina favorita foi a questão do interesse nos conteúdos tratados dentro da disciplina. As citações a seguir exemplificam algumas justificativas oferecidas dentro da categoria:

"Geografia. [...] tinha interesse em alguns conteúdos". (P1)

"História. Eu tenho um interesse profundo por esse assunto, que veio por pesquisa própria, o que tornou as aulas de histórias suportáveis, porque as professoras não ajudavam”. (P2)

"Biologia, pois era a matéria com os assuntos mais interessantes". (P3)

"Gostava de português. Sempre me fascinou a complexidade do idioma e sua lógica”. (P4)

"História, sempre me interessei [...]”. (P5)

"História, sempre gostei muito de filmes medievais e etc”. (P6)

“Matemática, sempre gostei de exatas”. (P7)

“Matemática, porque eu sempre fui interessado em nisso”. (P8)

"Física. Era uma matéria muito interessante, que nos desafiava todos os dias". (P9)

“História, pois gosto do assunto”. (P10)

"Geografia e história, por se encontrar com assuntos do meu interesse”. (P11) 


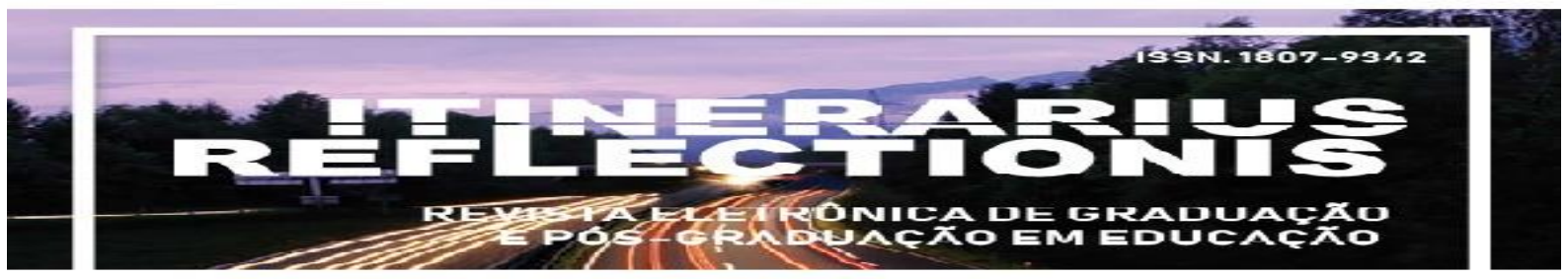

Volume, 15, número, 1, ano 2019

"Geografia e Biologia, sou apaixonado por ciência, eu via muitos documentários

e ficava encantado, isso acabou estimulando o meu gosto”. (P12)

“Física. Sempre gostei de números”. (P13)

“Literatura porque eu sempre gostei de ler". (P14)

O interesse dos alunos está intimamente relacionado com a motivação em aprender. Mesquita e Duarte (1996) afirmam que a motivação, por si só, é um conjunto de processos psicológicos e fisiológicos que levam o sujeito a agir desencadeando ações; Balancho e Coelho (1996) indicam que esta motivação ativa e dirige o aluno, estimulando-o a alcançar um determinado objetivo, como, por exemplo, aprender um determinado conteúdo. As motivações podem ser intrínsecas, quando advém do interior da pessoa, ou extrínsecas, que surgem a partir do ambiente externo (MORAES e VARELA, 2007).

O fator "interesse" é considerado como um dos componentes da motivação intrínseca do estudante (BORUCHOVITCH, 2009), e é constantemente relacionado como sinônimo de atenção, curiosidade, e inclusive de motivação em si. Ainda, o fator "interesse" é um forte preditivo do sucesso do estudante no ambiente escolar e também nas suas escolhas acadêmicas futuras (HAUER ET AL., 2008).

A literatura diferencia dois tipos de interesses: (a) Interesse individual, que é considerado um interesse mais profundo e estável, que tende a ser retroalimentado constantemente pelo sujeito, independente da atuação do professor; e (b) Interesse situacional, que é ativado a partir das condições proporcionadas pelo ambiente externo e é transitório, que pode ser alterado pela atuação do professor (ROTGANS e SCHMIDT, 2011). Aqui, os resultados dentro desta categoria são analisados a partir da visão de interesse individual dos participantes com relação a sua matéria favorita.

Invariavelmente e com o progresso dos estudos sobre o papel do interesse na aprendizagem, é cada vez mais recomendado que o professor busque conhecer os interesses individuais dos alunos, assim como acessar o conhecimento prévio dos mesmos (AUSUBEL ET AL., 1978; VYGOTSKY, 2010), a fim de utilizar ambos os dados na escolha e implementação de estratégias e planejamento de ensino (Fig. 3). Porém, devido à particularidade de cada ser humano, que é construída a partir das vivências durante o seu desenvolvimento, o fator "interesse" e sua origem são difíceis de serem identificados 


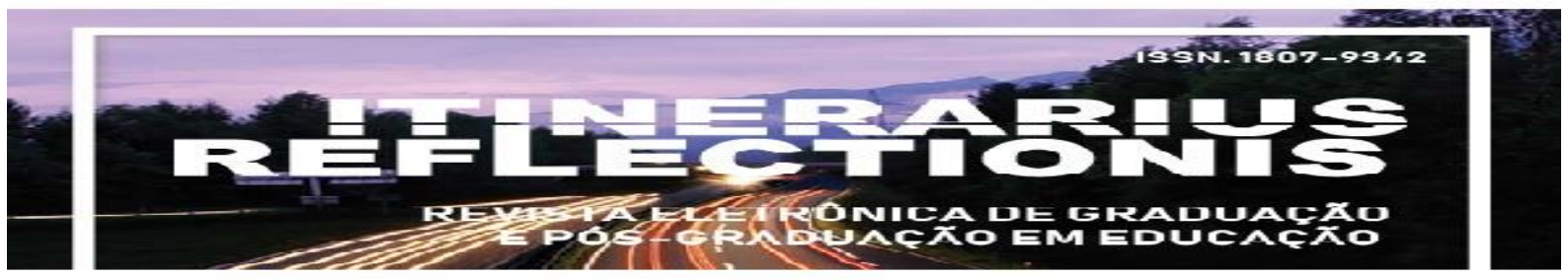

Volume, 15, número, 1, ano 2019

individualmente em cada estudante, e instrumentos da avaliação do interesse no contexto educacional são ainda escassos (RENNINGER e HIDI, 2011). As transcrições a seguir demonstram que alguns participantes conseguem indicar pontos que os fazem se interessar por determinado conteúdo:

"Matemática. Pois ou estava certo ou errado”. (P15)

"Física. Porque havia teoria e logo apareciam cálculos para serem solucionados". (P16)

"Matemática, porque é uma das poucas coisas na vida que se pode quantificar e que tem regras absolutas". (P17)

"Matemática, por ser uma matéria lógica”. (P18)

"Matemática. Nessa disciplina é sempre possível provar as respostas certas, não deixando espaço para opiniões ou subjetividade”. (P19)

"Matemática. Porque matemática é fácil, tudo faz sentido e eu conseguiria resolver um problema sem nunca ter visto ele antes, enquanto eu não saberia responder uma pergunta de história sem estudar”. (P20)

"Matemática quando pequeno, pois adorava números. Depois fiquei dividido entre as humanas". (P21)

Apesar de poucas, algumas técnicas estão disponíveis para a avaliação do interesse dos alunos: Rotgans (2015) realizou um estudo sobre os instrumentos de avaliação do interesse em contexto educacional e desenvolveu um Questionário de Interesse Individual - QII (traduzido de The Individual Interest Questionnaire - IIQ) que é um questionário padrão simples que pode ser adaptado para a coleta de informações sobre os interesses dos alunos em qualquer área da educação (ROTGANS, 2015: Appendix, p. 73); e Borges e Mendes (2007) adaptaram o Questionário sobre Interesse Pessoal por Temas de Estudo (QIPTE) com alto índice de coeficiente de confiabilidade, para investigar o interesse de professores, que pode ser modificado para conhecer os interesses dos estudantes. De posse dos elencos de interesse dos alunos em uma determinada sala de aula, o professor pode articular oportunidades educativas a fim ampliar e aprofundar estes interesses correlacionando-os com os conteúdos escolares. 


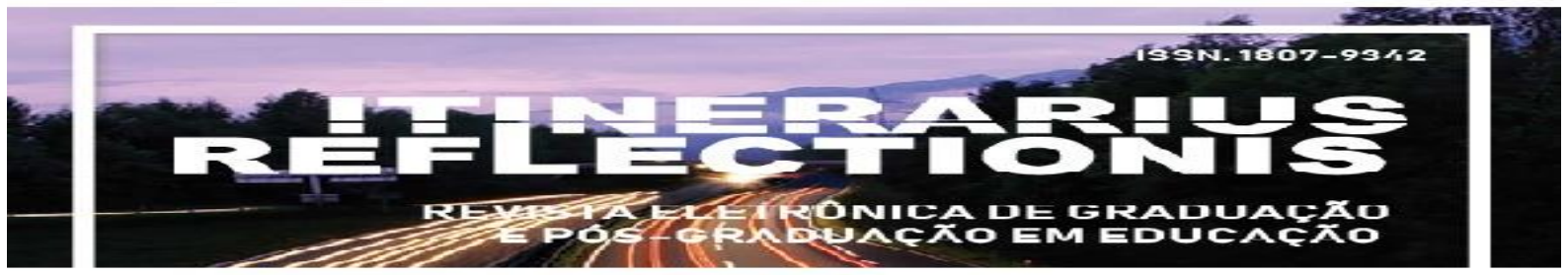

Volume, 15, número, 1, ano 2019

Ainda, diversos participantes disseram gostar de determinada disciplina pela sua facilidade de compreensão no conteúdo:

“Geografia. Tinha facilidade...”. (P22)

“História. Tinha facilidade...”. (P23)

“Matemática. [...] era fácil para mim”. (P24)

“Biologia, pois sempre tive facilidade na área e adorava as aulas no laboratório de biologia”. (P25)

"História. Desde cedo tive maior facilidade com textos". (P26)

"Física. Eu entendia mais do que a maioria dos alunos". (P27)

"Física. Gostava, pois eu assimilava o conteúdo por osmose”. (P28)

“Biologia. Questão de facilidade, e, curiosidade também”. (P29)

"Química orgânica, pois tinha facilidade”. (P30)

“Inglês. Pois tinha muita facilidade”. (P31)

Em estudos de expressão genética e desenvolvimento humano, os resultados de uma pesquisa com gêmeos idênticos (geneticamente iguais) e fraternais (geneticamente diferentes) sobre seus desempenhos no aprendizado concluíram que fatores genéticos influenciam, por exemplo, na facilidade do desenvolvimento das habilidades com letras e números (DAVIS ET AL., 2014). Diversas pesquisas semelhantes apontam que existe uma predisposição genética para a facilidade de aquisição de algumas habilidades ou compreensão em si de conteúdos de certas áreas. Assim, é compreensível que o fator "facilidade", como um fator natural, seja relacionado e influencie diretamente o fator "interesse" individual.

Porém, na visão psicopedagógica, as dificuldades de aprendizagem - e consequentemente as facilidades - estão mais associadas a situações comportamentais e emocionais durante o processo de ensino-aprendizagem (MARTURANO ET AL., 1993). Isto significa que o professor tem grande influência como mediador da facilidade e/ou dificuldade de aprendizagem do aluno. Dessa forma, identificar tanto as facilidades quanto as dificuldades dos alunos contribui para que o professor alcance os objetivos desejados de aprendizagem.

A análise das dificuldades, o reconhecimento dos interesses aliados às facilidades, e a avaliação do conhecimento prévio dos alunos compõem a base perfilar do público do professor (Fig. 3), e é o ponto de partida para a escolha das mediações pedagógicas. É 


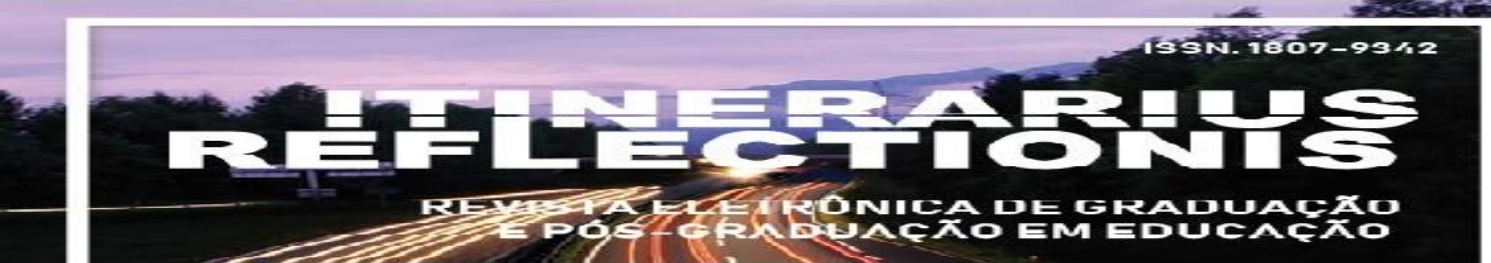

Volume, 15, número, 1, ano 2019

evidente que o professor sempre atua conforme a sua concepção do processo de ensino e de aprendizagem, porém os alunos são sujeitos transitórios em sua sala de aula e não são passíveis de generalizações, assim a mediação da ação educativa deve ser programada sempre a partir de novo contexto.

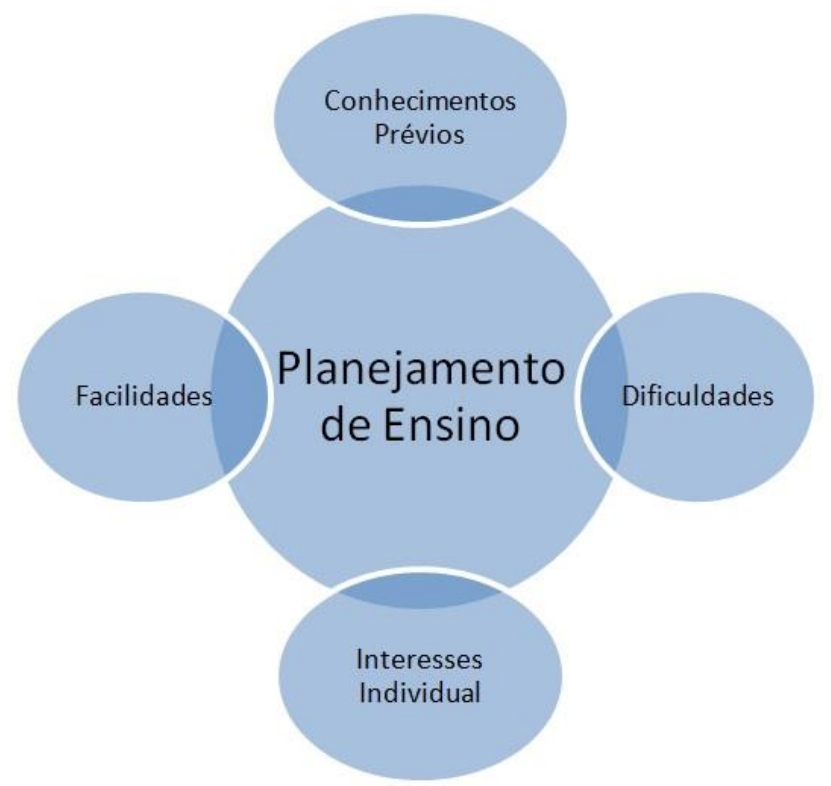

Figura 3. Elementos que promovem o conhecimento da base perfilar do estudante pelo professor a fim de direcionar o planejamento de ensino: Facilidades, Conhecimentos prévios, Dificuldades e Interesses Individual. Fonte: autora (2018).

\subsection{Fator interno: Fator professor}

O fator "professor" foi o segundo mais citado, com $28 \%$ de representatividade, como justificativa para a escolha da matéria favorita:

"História, por causa do professor". (P32)

"Sociologia, por causa da professora”. (P33)

“Ciências, por conta da professora”. (P34)

"Geografia, não sei por que exatamente, mas acredito que era por conta dos professores". (P35)

"Historia, devido ao professor". (P36) 


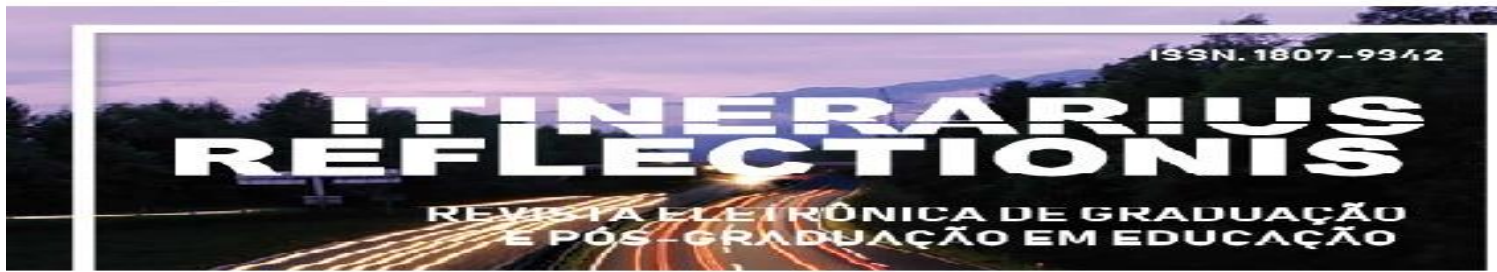

Volume, 15, número, 1, ano 2019

Respostas específicas de participantes demonstram o que diversas pesquisas apontam sobre a relação aluno-professor exercer um efeito motivador no aluno alterando o nível de esforço e empenho:

"Não sei dizer qual seria a favorita. Posso afirmar que quando lecionada por um professor que eu apreciava, a aula seria muito mais aprazível. Mas posso facilmente me ver odiando cada segundo sentado caso o professor fosse ruim". (P37)

"História, sempre tive ótimos professores que me levaram a gostar da matéria e querer entender as coisas em seu contexto temporal”. (P38)

De fato, a indicação da experiência positiva de aprendizado pela convivência escolar com "bons", "ótimos" e "excelentes" professores esteve presente em muitas respostas: "Matemática. Tive um bom professor e gosto de exatas". (P39)

"Difícil escolher só uma. Gostava muito de português. Tive ótimos professores". (P40)

"História, pois o professor era excelente”. (P41)

"História, tive uma boa professora". (P42)

"Geografia, porque a professora era ótima, o que me fazia gostar da matéria”. (P43)

"Matemática, sempre gostei de exatas e tive os melhores professores". (P44)

“Física, por ter um excelente professor”. (P45)

"História, pois o professor era excelente”. (P46)

"História. Sempre fui fascinada por todos os aspectos da história humana e como se dão processos históricos sócios econômicos e culturais mais a repetição de padrões, além disso, tive ótimos professores”. (P47)

"Biologia. tive um ótimo professor no ensino médio nos assuntos de fisiologia, genética, etc”. (P48)

"Inglês. Tive bons professores". (P49)

"Biologia e Geografia, pois os professores eram muito bons". (P50)

"Português, porque gostava do professor". (P51) 


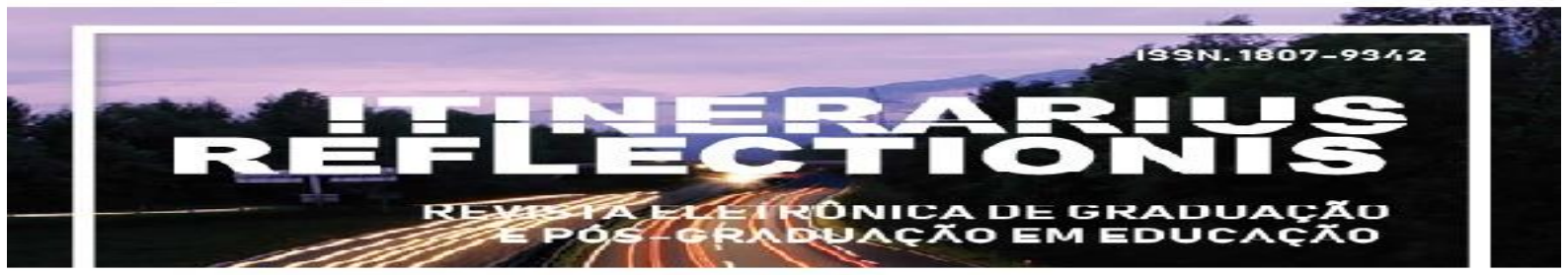

Volume, 15, número, 1, ano 2019

Em outras justificativas, alguns participantes relataram inclusive que a experiência com determinados professores e matérias foi motivador para a escolha pessoal de formação acadêmica:

"Geografia. É uma ciência bem abrangente e tive um excelente professor, o que me motivou a ingressar em uma faculdade de licenciatura em geografia”. (P52)

"Meus professores eram excelentes, acabei optando por cursar geografia devido a minha professora, porém ainda estou no primeiro periodo”. (P53)

"Química. O professor explicava muito bem como o mundo (nível atômico) funcionava. Aquilo me encantou. Hoje sou químico”. (P54)

Neste ponto é importante discutir o conceito do "bom professor" e as habilidades e qualidades que faz um professor se destacar. O dito "bom professor" é uma representação social construída a partir de múltiplos contextos da prática docente e nos diversos papéis (sociais, políticos) que este profissional assume na prática cotidiana (GISI ET AL., 2010). Assim, é fácil compreender que a visão do "bom professor" varia de pessoa para pessoa e de contexto para contexto, porém algumas habilidades e qualidades são recorrentemente conferidas e esperadas ao "bom docente". Essas habilidades e qualidades são entrelaçadas em dimensões humana, técnica e ideológica (VENTURA ET AL., 2011).

Campos et al. (2010) observaram que cinco categorias de habilidades estão mais associadas contendo qualidades positivas esperadas de professores: Habilidades sociais e interpessoais, que envolve qualidades como simpatia, compreensão, paciência, atenção e educação pessoal; Habilidades pedagógicas, como comunicação, oratória, dinamismo e rigor; Habilidades cognitivas, como inteligência e conhecimento; Habilidades organizacionais, como organização, responsabilidade e pontualidade; e Ética, como respeito e honestidade. Aqui, os participantes indicaram ao menos seis categorias e três habilidades relacionadas.

Algumas habilidades sociais e interpessoais do professor foram indicadas nas qualidades de afetividade e aproximação entre o aluno e o professor:

"Física. O professor se importava”. (P55)

“Geografia, professora dedicada”. (P56)

“Física. O professor era muito próximo de nós”. (P57) 


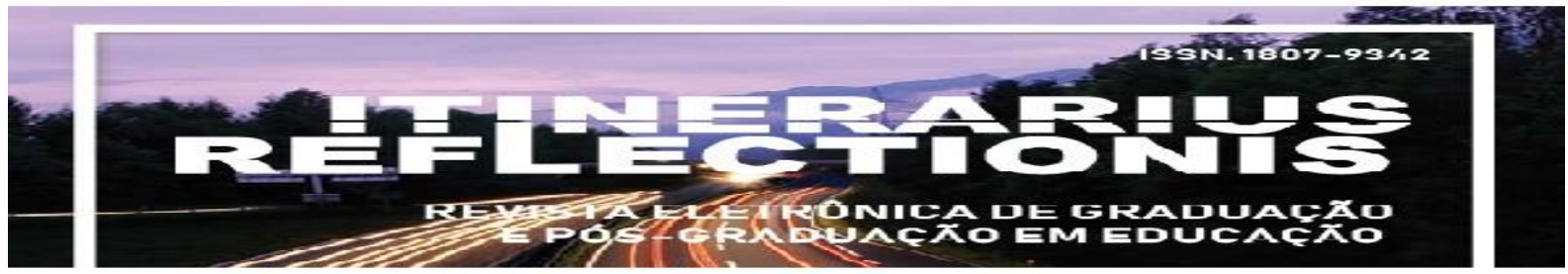

Volume, 15, número, 1, ano 2019

"Português, pois os professores eram críticos e valorizavam a aprendizagem do aluno”. (P58)

Os participantes também indicaram a importância do nível de conhecimento dos professores como habilidade cognitiva positiva:

"Sociologia, porque as discussões eram muito interessantes e o professor era inteligentíssimo e sabia muito”. (P59)

Porém, as habilidades pedagógicas foram as mais frequentes nas respostas dos participantes. A didática, oratória e clareza foram retratadas na forma do professor em oferecer aulas diferenciadas, mais interativas e com transmissão coerente de conteúdo:

"História. Eram aulas geralmente mais interativas". (P60)

"Filosofia até ano passado. O professor era muito bom, humilde, conseguia dar a matéria de forma clara e coerente, além da matéria em si ser muito interessante por ter contato com novas formas de pensar, por abrir a mente a novas ideias, entender em parte por que a sociedade é do jeito que é, etc”. (P61)

"História, porque o professor dava aulas como se estivesse narrando uma história, um filme”. (P62)

“Matemática. O meu professor sempre foi muito bom em ensinar”. (P63)

"Biologia. Nunca tive uma afinidade muito grande pela matéria em si, mas o professor conseguia fazer tudo fazer sentido e deixar a aula apaixonante”. (P64)

“Química, porque meu professor levava um monte de experimentos legais”. (P65)

"Geografia. O professor passava o conteúdo de maneira interessante e em geral tratava de temas mais atuais”. (P66)

"Dependendo do ano, pois dependia também do método de ensino de cada professor”. (P67)

“Física. O professor possuía uma didática excelente”. (P68)

"Sociologia, porque o professor era muito bom e conseguia lecionar o conteúdo e ainda trazia debates e discussões sobre assuntos atuais". (P69)

“Química, gostava da metodologia do professor”. (P70) 


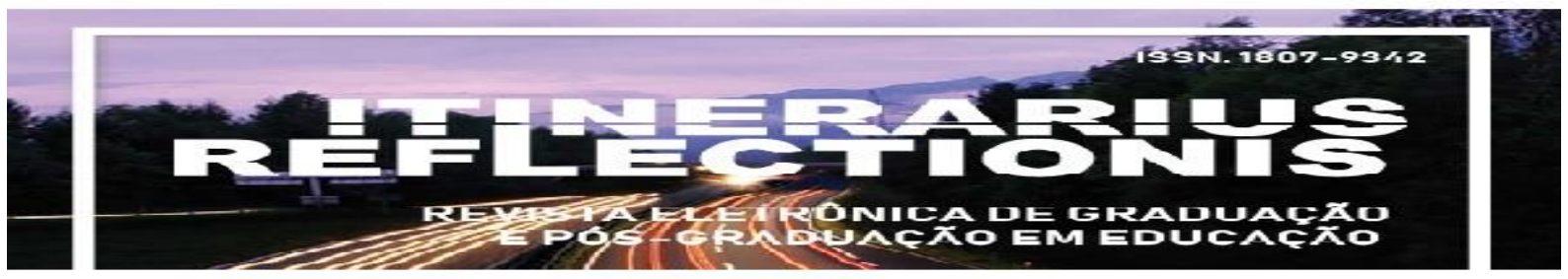

Volume, 15, número, 1, ano 2019

"História, pois o professor sabia ensinar a matéria de forma não maçante, fazendo o aluno refletir, e se separando de qualquer ideologia, fazendo uma análise o mais imparcial possível de cada assunto”. (P71)

“Química, porque o professor ensinava muito bem”. (P72)

"Química, justamente pela dinâmica do professor, que me agradava. A matéria se tornava fácil (pra mim pelo menos)”. (P73)

“Filosofia, o modo em que o professor apresentava e trazia discussões”. (P74)

"Eu sempre gostei de português porque era a que mais fugia do padrão em suas didáticas, trazendo literatura e produção de texto. Não focava apenas em decorar conceitos". (P75)

Algumas respostas dos participantes demonstraram que o uso de certas estratégias pedagógicas motivaram o aprendizado e o gosto pelas disciplinas. $\mathrm{O}$ uso da aproximação do conteúdo com o dia-a-dia do aluno, ou seja, o contexto das matérias em seu cotidiano, foi a ferramenta mais citada como uma das formas de motivação ao aprendizado:

"Geografia. Sempre foi minha matéria favorita por envolver conhecimentos de outras disciplinas das quais eu também gostava (geografia física, ecologia, história, etc.), o que me permitia perceber a interação destas matérias em um contexto real". (P76)

“Física. Eu [...] conseguia ver a praticidade do que eu aprendia”. (P77)

“Geografia. Mapas; grande utilidade para a vida fora da sala de aula”. (P78)

“Física, pois era a que eu mais via na vida real”. (P79)

"Física, porque é interessante como ela consegue fazer as coisas do mundo pararem de parecer mágica e fazerem sentido”. (P80)

“Biologia, pois não é uma disciplina abstrata, posso ver exemplos claros na vida fora da escola”. (P81)

"Matemática, pela facilidade de associação com a vida real”. (P82)

"Biologia. Porque é uma matéria que traz conhecimentos e aplicações práticas na vida e no entendimento do mundo e de como as coisas funcionam”. (P83)

Os aspectos profissionais e pessoais do professor apontados pelos participantes mostram que a relação professor/aluno tem importante papel na atividade construtiva para o 


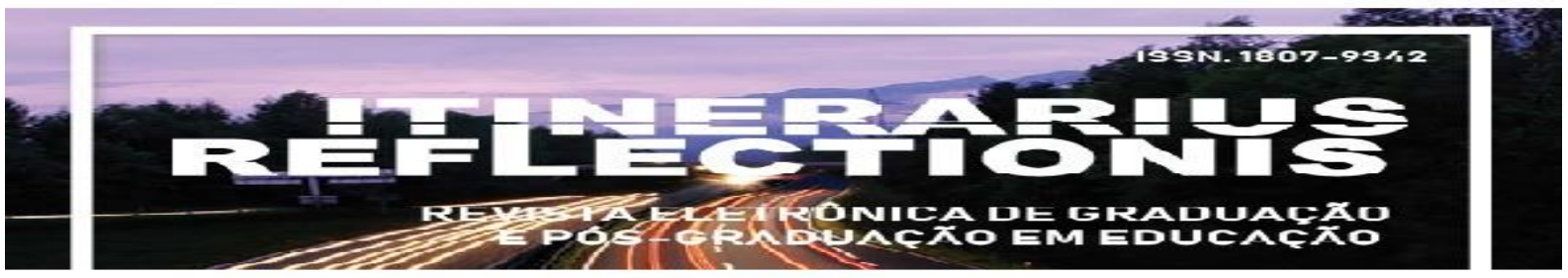

Volume, 15, número, 1, ano 2019

processo de ensino-aprendizagem e podem gerar aversões ou afinidades curriculares. Assim, cabe ao professor conhecer e identificar o seu papel no contexto escolar e o seu impacto na vida do aluno, sabendo reconhecer os fatores que influenciam em sua competência, e não se colocar como mero transmissor de informações. Porém, convêm também lembrar que a relação construída em sala de aula entre o aprendiz e o mestre é bi-direcional, ou seja, tanto o professor quanto o aluno influenciam positivamente ou negativamente o outro. Assim, cabe a ambos os sujeitos à compreensão do papel recíproco na motivação no ambiente escolar e no processo de melhoria da qualidade da educação no Brasil.

\section{CONCLUSÃO}

A partir da análise das justificativas da escolha da matéria preferida pelos participantes, é possível concluir que fatores multidimensionais interferem na motivação do sujeito dentro do contexto escolar. $O$ interesse individual e as experiências na relação aluno/professor foram os principais fatores indicados na escolha da preferência por determinada disciplina.

O interesse individual é resultado de fatores fisiológicos, como predisposição genética, e psicológicos, enquanto o fator "professor" é dirigido por relações sociais e interpessoais entre o discente e docente. Dessa forma, o conhecimento do interesse natural do aluno pelo professor, juntamente com a investigação das facilidades, dificuldades e conhecimentos prévios pode formar uma ferramenta potencializadora positiva do processo de ensino-aprendizagem.

Finalmente, é essencial a contínua análise articulada dos diferentes aspectos que interferem no processo de ensino-aprendizagem com aporte em diferentes áreas da pesquisa. Constantes estudos de levantamento, impacto e influência dos fatores externos e internos que interferem no contexto escolar e na formação educacional dos alunos são fundamentais para a avaliação, em escalas diversas, da educação brasileira.

\section{REFERÊNCIAS}




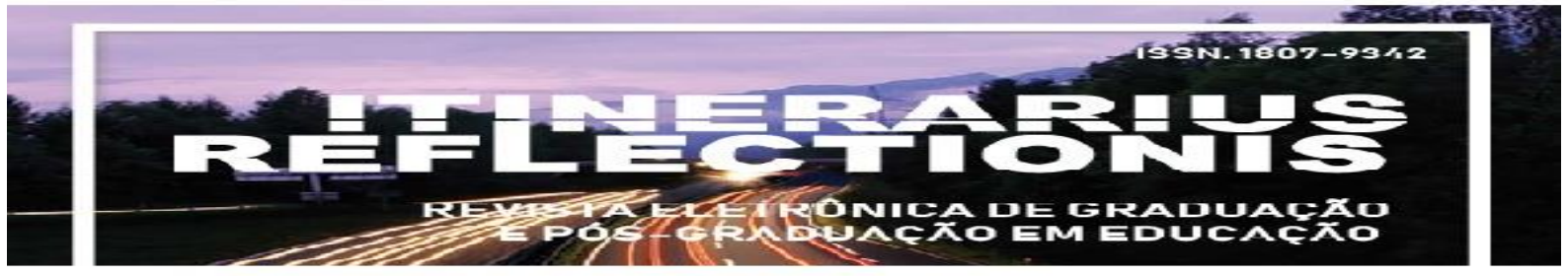

Volume, 15, número, 1, ano 2019

ALBERNAZ, A.; FERREIRA, F. H. G.; FRANCO, C. Qualidade e equidade no ensino fundamental brasileiro. Pesquisa e Planejamento Econômico, Rio de Janeiro: Editora Quartet, 2002. Disponível em: 〈http://ppe.ipea.gov.br/index.php/ppe/article/viewFile/139/74> Acesso em 14 nov. 2018.

AUSUBEL, D. P.; NOVAK, J. D.; HANESIAN, H. Educational psychology: a cognitive view. Holt, Rinehardt \& Winston, Nova York, 1978.

BALANCHO, M. J. S.; COELHO, F. M. Motivar os alunos, criatividade na relação pedagógica: conceitos e práticas. 2 ed. Porto: Portugal, 1996.

BARDIN, L. Análise de conteúdo. 4 ed. Lisboa, 2010.

BORGES, O.; MENDES, I. Um questionário sobre o interesse pessoal por temas de biologia. In: ANAIS DO VI ENCONTRO NACIONAL DE PESQUISA EM EDUCAÇÃO EM CIÊNCIAS, Florianópolis, Universidade Federal de Santa Catarina, 2007. Disponível em: <http://www.nutes.ufrj.br/abrapec/vienpec/CR2/p1047.pdf > Acesso em 14 nov. 2018.

BORUCHOVITCH, E. A motivação do aluno. 4 ed. Rio de Janeiro: Editora Vozes, 2009.

BUENO, B. O. Histórias de vida e autobiografias na formação de professores e profissão docente (Brasil, 1985-2003). Revista Educação e Pesquisa, São Paulo, v.32, n.2, p. 385-410, Maio./Ago, 2006. Disponível em: 〈http://dx.doi.org/10.1590/S1517-97022006000200013> Acesso em 14 nov. 2018.

CAMPOS, L. et al. Características de um bom professor na concepção dos acadêmicos do curso de odontologia da Universidade do Vale do Itajaí - UNIVALI. Revista da ABENO, v.10, n.1, $\quad$ p. $2010.13, \quad$ Disponível em: <https://revabeno.emnuvens.com.br/revabeno/article/download/2/2 > Acesso em 14 nov. 2018. 


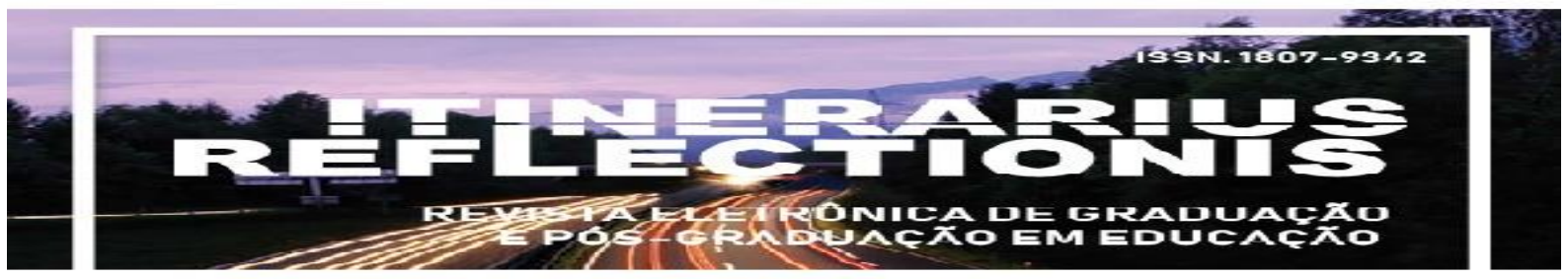

Volume, 15, número, 1, ano 2019

COLLARES, C. A. L. Ajudando a desmistificar o fracasso escolar. In: COLLARES, C. A. L.; MOYSÉS, M. A. M. (Orgs.). Preconceito no Cotidiano Escolar - Ensino e Medicalização. São Paulo, Campinas: Cortez, Edunicamp, p. 24-28, 1996. Disponível em: < http://evoluireducacional.com.br/wp-content/uploads/2012/08/COLLARES-C.A.L.Ajudando-a-Desmistificar-o-Fracasso-Escolar.pdf> Acesso em 14 nov. 2018.

DAVIS, O. S. P. et al. The correlation between reading and mathematics ability at age twelve has a substantial genetic component. Nature Communications, v.5, n.4204, 2014. Disponível em: < https://doi.org/10.1038/ncomms5204> Acesso em 14 nov. 2018.

DOURADO, L. F.; OLIVEIRA, J. F. A qualidade da educação: perspectivas e desafios. Cadernos CEDES, v.29, n.78, p. 201-215, 2009. Disponível em: <http://www.scielo.br/pdf/ccedes/v29n78/v29n78a04.pdf> Acesso em 14 nov. 2018.

FALCO, G. P.; SOARES-JÚNIOR, F. J.; ALTAF, J. G. Avaliação da demanda por novos cursos de ensino superior na cidade de Juiz de Fora. In: ANAIS DO XI SIMPÓSIO DE EXCELÊNCIAS EM GESTÃO E TECNOLÓGIA. Resende, Rio de Janeiro, 2014. Disponível em: <https://www.aedb.br/seget/arquivos/artigos14/38020246.pdf> Acesso em 14 nov. 2018.

FERREIRA, S. H. A.; BARREIRA, S. D. Ambiente familiar e aprendizagem escolar com alunos da educação infantil. Psicologia. Porto Alegre, PUCRS, v.41, n.4, p. 462-472, Out./Dez, 2010. Disponível em: <http://revistaseletronicas.pucrs.br/ojs/index.php/revistapsico/article/view/5686/5954> Acesso em 14 nov. 2018.

GARRIDO, I. Motivacion, emocion y accion educativa. In: MAYOR, L.; TORTOSA, F. (Eds.). Âmbitos de aplicacion de la psicologia motivacional. Bilbao: Desclee de Brower, 1990. 

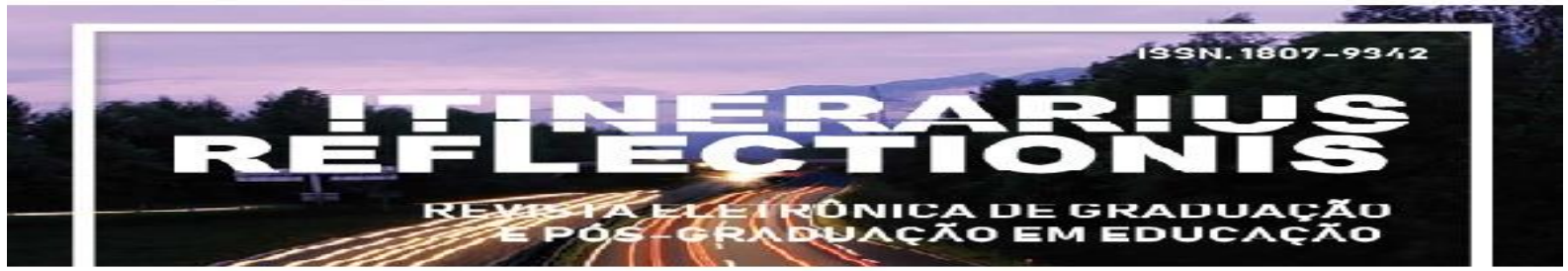

Volume, 15, número, 1, ano 2019

GATTI, B., et al. A reprovação na $1^{\text {a }}$ série do $1^{\circ}$ grau: um estudo de caso. Cadernos de pesquisa, v.38, $\quad$ p. 3-13, 1981. Disponível em: <http://publicacoes.fcc.org.br/ojs/index.php/cp/article/view/1608/1601> Acesso em 14 nov. 2018.

GISI, M. L.; ENS, R. T.; EYNS, A. M. Políticas educacionais e a representação de estudantes de pedagogia sobre o que é um "bom professor". Educação, Sociedade \& Cultura, v.31, $\quad$ p. 51-65, 2010. Disponível em: <https://www.fpce.up.pt/ciie/revistaesc/ESC31/ESC31_MLGisi_051-066.pdf> Acesso em 14 nov. 2018.

HAUER, K. E. et al. Factors associated with medical students' career choices regarding internal medicine. Jama, v.300, n.10, p. 1154-1164, 2008. Disponível em: <https://doi.org/10.1001/jama.300.10.1154> Acesso em 14 nov. 2018.

JAMNIK, M. R.; LANE, D. J. The Use of Reddit as an Inexpensive Source for High-Quality Data. Practical Assessment, Research \& Evaluation, v.22, n.5, 2017. Disponível em: $\langle$ http://pareonline.net/getvn.asp? $\mathrm{v}=22 \& \mathrm{n}=5>$ Acesso em 14 nov. 2018.

LENS, W. Motivation and learning. In: HUSEN, T.; POSTLETHWAITE, T. N. (Orgs.). The international encyclopedia of education, v.7, p. 3936-3942. United States: Pergamon, 1994.

LIBÂNEO, J. C. Organização e gestão da escola: teoria e prática. 1 ed. Goiânia: Editora Alternativa, 2001.

LIBÂNEO, J. C.; FERREIRA, J.; SEABRA, M. Educação escolar: políticas, estrutura e organização. 6 ed. São Paulo: Cortez, 2008. 


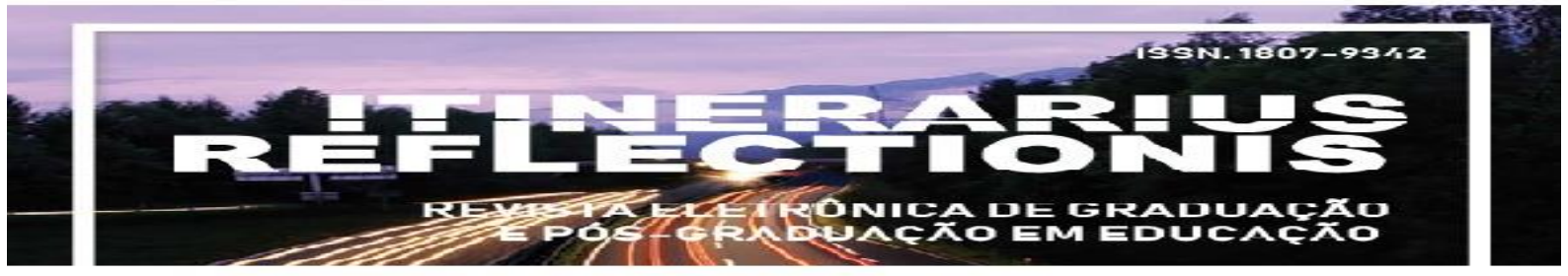

Volume, 15, número, 1, ano 2019

LORENZONI, L. S. et al. Disciplinas que despertam mais e menos interesse nos alunos do ensino médio da E.E.E.F.M. Professora Célia Teixeira do Carmo. In: ANAIS DO XVII ENCONTRO LATINO AMERICANO DE INICIAÇÃO CIENTÍFICA, XIII ENCONTRO LATINO AMERICANO DE PÓS GRADUAÇÃO, E VII ENCONTRO LATINO AMERICANO DE INICIAÇÃO CIENTÍFICA JÚNIOR. Universidade do Vale do Paraíba, 2017.

Disponível

em:

<http://www.inicepg.univap.br/cd/INIC_2012/anais/arquivos/0971_0768_01.pdf> Acesso em 14 nov. 2018.

MARTURANO, E. M.; LINHARES M. B. M.; PARREIRA V. L. C. Problemas emocionais e comportamentais associados a dificuldades na aprendizagem escolar. Medicina Ribeirão Preto, v.26, n.2, p. 161-175, 1993. Disponível em: <http://www.scielo.br/pdf/epsic/v11n1/12.pdf> Acesso em 14 nov. 2018.

MESQUITA, R.; DUARTE, F. Dicionário de psicologia. Lisboa: Plátano Editora, S. A, 1996.

MORAES, C. R.; VARELA, S. Motivação do aluno durante o processo de ensino e aprendizagem. Revista Eletrônica de Educação. Londrina, v.1, n.1, Ago./Dez., p. 1-15, 2007. Disponível em: 〈http://web.unifil.br/docs/revista_eletronica/educacao/Artigo_06.pdf $>$ Acesso em 14 nov. 2018.

NOVOA, A. Os professores e suas histórias de vida. In: NOVOA, A.(Org). Vidas de professores. Tradução de Maria dos Anjos Caseiro, Manuel Figueiredo Ferreira. Porto: Porto Editora, 1992.

PINTRICH, P. R.; SCHUNK, D. H. Motivation in education - theory, research and applications. New Jersey: Merril Prentice Hall, 2002. 


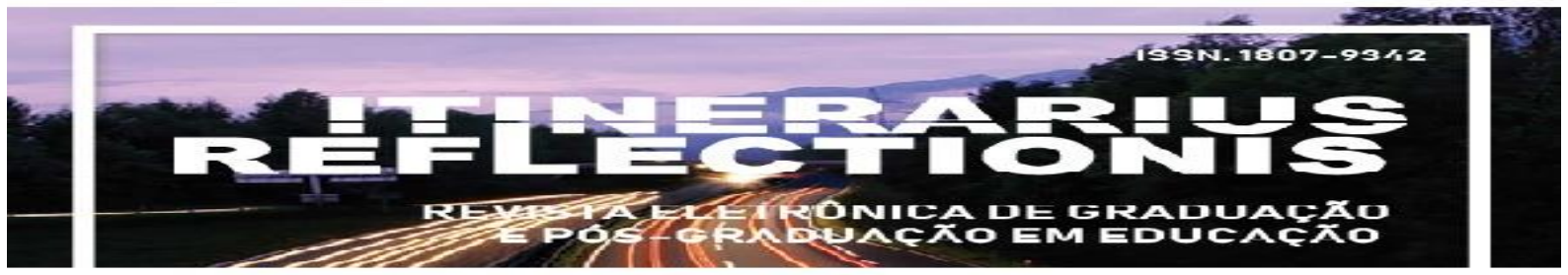

Volume, 15, número, 1, ano 2019

RENNINGER, K. A.; HIDI, S. Revisiting the conceptualization, measurement, and generation of interest. Educational Psychologist, v.46, n.3, p. 168-184, 2011. Disponível em: <https://doi.org/10.1080/00461520.2011.587723> Acesso em 14 nov. 2018.

ROTGANS, J. I. Validation Study of a General Subject-matter Interest Measure: The Individual Interest Questionnaire (IIQ) Health Professions Education, v.1, n.1, p. 67-75, 2015. Disponível em: 〈https://doi.org/10.1016/j.hpe.2015.11.009> Acesso em 14 nov. 2018.

ROTGANS, J. I.; SCHMIDT, H.G. The role of teachers in facilitating situational interest in an active--learning classroom. Teaching and Teacher Education, v.27, n.1, p. 37-42, 2011. Disponível em: <https://doi.org/10.1016/j.tate.2010.06.025> Acesso em 14 nov. 2018.

SHATZ, I. Fast, Free, and Targeted: Redditas a Source for Recruiting Participants Online. Social Science Computer Review, v.35, n.4, p. 537-549, 2016. Disponível em: <https://doi.org/10.1177/0894439316650163> Acesso em 14 nov. 2018.

SHAYWITZ, S. Entendendo a dislexia. Porto Alegre: Artmed, 2006.

SOARES, J. F. O efeito da escola no desempenho cognitivo de seus alunos. In: SOUZA, A. M. (Ed.). Dimensões da Avaliação Educacional. Petrópolis: Vozes, 2005. Disponível em: <http://www.redalyc.org/pdf/551/55120207.pdf> Acesso em 14 nov. 2018.

SOARES, J. F.; ALVES, M. T. G.; MARI, F. O. Avaliação de escolas de ensino básico. In: FREITAS, L. C. (Ed.). Avaliação de Escolas e Universidades. Campinas: Komedi, 2003.

SOARES, J. F. et al. Exclusão interescolar nas escolas públicas brasileiras: Um estudo com dados da Prova Brasil de 2005, 2007 e 2009. Brasília: Editora da UNESCO, 2012. Disponível em: <http://unesdoc.unesco.org/images/0021/002160/216055por.pdf> Acesso em 14 nov. 2018. 


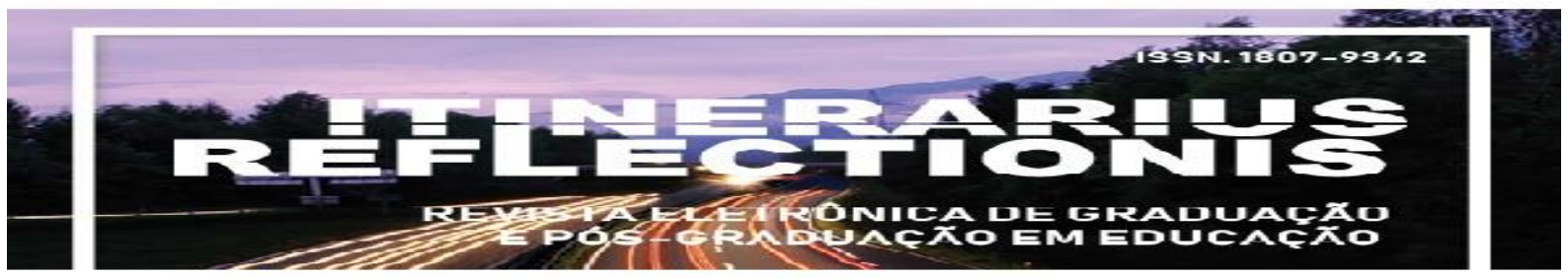

Volume, 15, número, 1, ano 2019

SORROCHE, E. M. Perspectivas dos alunos do ensino fundamental I quanto às aulas de educação física. In: ANAIS DO III ENCONTRO CIENTÍFICO E SIMPÓSIO DE EDUCAÇÃO UNISALESIANO, Lins, 2011. Disponível em: <http://www.unisalesiano.edu.br/simposio2011/publicado/artigo0121.pdf> Acesso em: 14 nov. 2018.

SOARES, T. M. et al. Fatores associados ao abandono escolar no ensino médio público de Minas Gerais. Educação e Pesquisa, v.41, n.3, p. 757-772, Ju./Set, 2015. Disponível em: <http://www.scielo.br/pdf/ep/v41n3/1517-9702-ep-41-3-0757.pdf> Acesso em: 14 nov. 2018.

VARGAS, J. C. M.; LOPES, L. A.; LOPES, P. T. C. Preferências de disciplinas curriculares dos alunos do $1^{\circ}$ ano do ensino médio em uma escola particular de Canoas, RS. In: ANAIS DO $3^{\circ}$ COLÓQUIO ULBRA DE EXTENSÃO, PESQUISA E ENSINO E $3^{\circ}$ ENCONTRO ULBRA DE BOLSISTAS CNPQ E FAPERGS, 2017. Disponível em: <http://www.eventos.ulbra.br/index.php/eucf/eucf3/paper/viewFile/2663/1261> Acesso em: 13 nov. 2018.

VENTURA, M. C. A. A. et al. O "bom professor" - opinião dos estudantes. Revista de Enfermagem Referência, v.3, n.5, Dez, 2011.

VIEIRA, M. C. Matemática é a matéria favorita das crianças brasileiras, revela pesquisa. Revista Crescer, Texto jornalístico de 02 de Abril de 2014. Disponível em: $<$ https://revistacrescer.globo.com/Criancas/Escola/noticia/2014/04/matematica-e-a-materiafavorita-das-criancas-brasileiras-revela-pesquisa.html>. Acesso em: 8 jun. 2018.

VIEIRA, B. C. R. et al. Disciplinas de maior e menor interesse dos alunos de séries iniciais de uma escola pública do município de Jerônimo Monteiro - ES. In: ANAIS DO XVII ENCONTRO LATINO AMERICANO DE INICIAÇÃO CIENTÍFICA, XIII ENCONTRO LATINO AMERICANO DE PÓS GRADUAÇÃO, E VII ENCONTRO LATINO AMERICANO DE INICIAÇÃO CIENTÍFICA JÚNIOR. Universidade do Vale do 


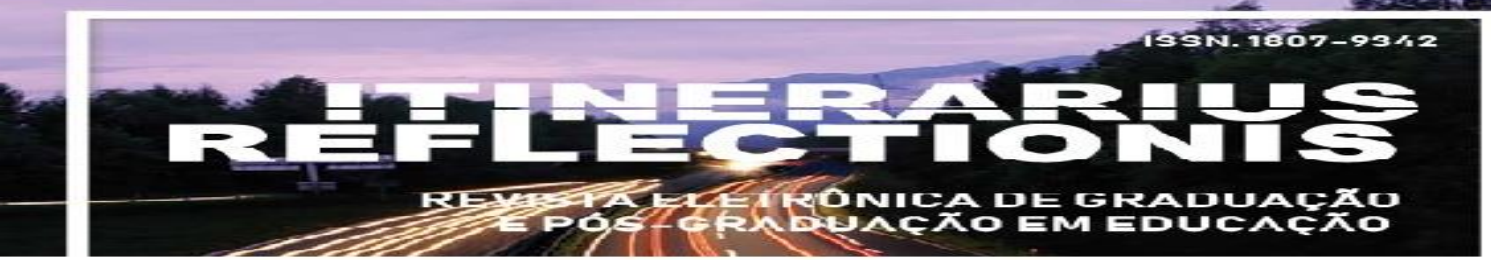

Volume, 15, número, 1, ano 2019

Paraíba,

2017.

Disponível

em:

<http://www.inicepg.univap.br/cd/INIC_2013/anais/arquivos/0274_0450_01.pdf> Acesso em: 13 nov. 2018.

VYGOTSKY, L. S. A construção do pensamento e da linguagem. 2. ed. São Paulo: Martins Fontes, 2010.

WILlCUTT, E. G. et al. Comorbidity between reading disability and math disability: concurrent psychopathology, functional impairment, and neuropsychological functioning. Journal of Learning Disabilities, v.46, n.6, p. 500-516, 2013. Disponível em: <https://doi.org/10.1177/0022219413477476> Acesso em: 14 nov. 2018. 